\title{
Quizartinib, a selective FLT3 inhibitor, maintains antileukemic activity in preclinical models of RAS-mediated midostaurin- resistant acute myeloid leukemia cells
}

\author{
Tomoya Aikawa ${ }^{1}$, Noriko Togashi ${ }^{1}$, Koichi Iwanaga ${ }^{1}$, Hiroyuki Okada ${ }^{1}$, Yumi \\ Nishiya $^{1}$, Shinichi Inoue ${ }^{1}$, Mark J. Levis ${ }^{2}$ and Takeshi Isoyama ${ }^{1}$ \\ ${ }^{1}$ Daiichi Sankyo Co., Ltd., Tokyo, Japan \\ ${ }^{2}$ The Sidney Kimmel Comprehensive Cancer Center at Johns Hopkins University, Baltimore, MD, United States of America \\ Correspondence to: Takeshi Isoyama, email: isoyama.takeshi.y5@daiichisankyo.co.jp \\ Keywords: relapsed/refractory AML; FLT3 inhibitors; quizartinib; AC886; midostaurin resistance \\ Received: November 20, $2019 \quad$ Accepted: January 29, $2020 \quad$ Published: March 17, 2020
}

Copyright: Aikawa et al. This is an open-access article distributed under the terms of the Creative Commons Attribution License 3.0 (CC BY 3.0), which permits unrestricted use, distribution, and reproduction in any medium, provided the original author and source are credited.

\section{ABSTRACT}

FLT3 internal tandem duplication (ITD) mutations are associated with poor prognosis in patients with acute myeloid leukemia (AML). In this preclinical study, we characterized the binding affinity and selectivity of quizartinib, a small-molecule inhibitor of FLT3, and AC886, the active metabolite of quizartinib, compared with those of other FLT3 inhibitors. Selectivity profiling against $>\mathbf{4 0 0}$ kinases showed that quizartinib and AC886 were highly selective against FLT3. Quizartinib and AC886 inhibited FLT3 signaling pathways in FLT3-ITD-mutated AML cells, leading to potent growth inhibition with $\mathrm{IC}_{50}$ values of $<1 \mathrm{nM}$. When quizartinib was administered to mice bearing FLT3-ITD mutated tumors, AC886 was rapidly detected and tumor regression was observed at doses of $\geq 1 \mathrm{mg} / \mathrm{kg}$ without severe body weight loss. In addition, quizartinib inhibited the viability of midostaurin-resistant MOLM-14 cells and exerted potent antitumor activity in mouse xenograft models without severe body weight loss, while midostaurin and gilteritinib did not show significant antitumor effects. This is the first detailed characterization of quizartinib and AC886 in comparison with other FLT3 inhibitors under the same experimental conditions. Preclinical antileukemic activity in midostaurin-resistant FLT3-ITD-mutated AML cells suggests the potential value of quizartinib following midostaurin failure in patients with FLT3-ITD mutated AML.

\section{INTRODUCTION}

FMS like tyrosine kinase 3 (FLT3) is a receptor tyrosine kinase expressed by acute myeloid leukemia (AML) cells in $70 \%$ to $90 \%$ of patients [1]. FLT3 mutations have been found in approximately $30 \%$ of AML cases, with internal tandem duplication (ITD), commonly found in the juxtamembrane domain of FLT3, occurring in approximately $25 \%$ of cases and mutations in the tyrosine kinase domain (TKD) present in approximately $5 \%$ [2-5]. FLT3-ITD is the most common form of FLT3 mutation and is associated with a higher rate of relapse and poorer clinical outcomes [6,7], while FLT3-TKD mutations have not been definitively linked to poor prognosis [8]. The FLT3-ITD mutations constitutively activate FLT3 signaling, acting through the PI3 kinase/AKT and MEK/
ERK pathways, as well as STAT5, both from the cell membrane and as an immature form originating from the endoplasmic reticulum [9-11].

FLT3 tyrosine kinase inhibitors are classified into 2 categories. Type I, including midostaurin, gilteritinib, and crenolanib, which bind the active conformation of FLT3, and type II, including quizartinib and sorafenib, which bind the inactive conformation $[12,13]$. FLT3 inhibitors vary considerably in kinase selectivity [14]. Generally, type II inhibitors are more selective than type I inhibitors, as the inactive conformation preferred by type II inhibitors is thought to be more kinase specific than the active conformation [15]. It is speculated that highly selective FLT3 inhibitors can be administered at lower doses, improving tolerability and minimizing off-target effects. The type II FLT3 inhibitor quizartinib demonstrated high 
kinase selectivity [16], but its active metabolite AC886 has not been characterized.

AML relapse is associated with the accumulation of additional genetic mutations and clonal evolution, which is shaped by the primary treatment regimen received [17]. Secondary kinase mutations can emerge in FLT3-ITD AML, resulting in resistance to FLT3 inhibitors, and point mutations that confer resistance to a certain FLT3 inhibitor tend to have cross-resistance to other drugs in the same class [18].

Agents that treat AML by targeting FLT3 are beginning to be approved, yet limited options remain. Midostaurin $\left(\right.$ RYDAPT $\left.^{\circledR}\right)$ is the only approved FLT3 inhibitor for newly diagnosed FLT3 mutation-positive AML and is administered in combination with standard cytarabine and daunorubicin induction and cytarabine consolidation [19, 20]. Gilteritinib $\left(\right.$ XOSPATA $^{\mathbb{R}}$ ) was recently approved for the treatment of relapsed or refractory FLT3 mutation-positive AML [2123]. Quizartinib prolonged survival in patients with relapsed/ refractory FLT3-ITD-positive AML compared with salvage chemotherapy [24], and quizartinib (VANFLYTA ${ }^{\circledR}$ ) was recently approved in Japan. Limited data exist on the efficacy of available FLT3 inhibitors in patients with AML that was relapsed or refractory to a first-line midostaurin-based therapy, and strategies to overcome resistance mutations, such as a combination of inhibitors or use of more potent FLT3 inhibitors, are being evaluated [25].

The objectives of this preclinical study were to characterize the kinase binding affinity and selectivity of quizartinib and its active metabolite AC886 compared with those of other FLT3 inhibitors, to evaluate the antitumor effect of quizartinib on midostaurin-resistant AML cells, and to assess the impact of midostaurin resistance on FLT3 inhibitors.

\section{RESULTS}

\section{Quizartinib and its active metabolite AC886 bound to FLT3 with high affinity and selectivity}

The binding affinities of the type I FLT3 inhibitors midostaurin, gilteritinib, and crenolanib and type II FLT3 inhibitors sorafenib, quizartinib, and its metabolite AC886 (Figure 1A) were evaluated under the same experimental conditions against a panel of 404 nonmutant kinases. Both quizartinib and its active metabolite AC886 bound to FLT3 with high affinity, with Kd values of 3.3 and $1.1 \mathrm{nM}$, respectively (Figure 1B; Supplementary Table 1; Supplementary Appendix). The Kd values of other FLT3 inhibitors for FLT3 binding were $7.9 \mathrm{nM}$ (midostaurin), $1.0 \mathrm{nM}$ (gilteritinib), $0.28 \mathrm{nM}$ (crenolanib), and $5.9 \mathrm{nM}$ (sorafenib) (Figure 1; Supplementary Table 1; Supplementary Appendix).

Quizartinib was highly selective; among the 404 nonmutant kinases evaluated, quizartinib bound to FLT3 with the greatest affinity and bound only 2 kinases with $\mathrm{Kd}<10 \mathrm{nM}$ (FLT3 and KIT). In addition to FLT3, quizartinib and AC886 each bound 7 other kinases with $\mathrm{Kd}<100 \mathrm{nM}$, while the other inhibitors evaluated bound between 19 and 83 other kinases with that affinity (Table 1; Supplementary Appendix). Kinases that were bound by FLT3 inhibitors with $\mathrm{Kd}<1 \mathrm{nM}$ were KIT for AC886; ALK for gilteritinib; and MEK5, PDGFR $\alpha$, and ULK2 for crenolanib. To assess off-target inhibition, the inhibitory activities of quizartinib and AC 886 were assessed against a panel of 87 off-target molecules such as G-protein-coupled receptors, transporters, ion channels, nuclear receptors, and enzymes. Quizartinib and AC886 showed $>50 \%$ inhibition against only 2 and 3 molecules, respectively, at a high concentration of $10 \mu \mathrm{M}$, suggesting that these compounds had minimal off-target inhibitory activity (Supplementary Table 2).

\section{Quizartinib and AC886 had similarly potent and durable inhibition of FLT3 signaling in FLT3- ITD AML cells}

Quizartinib and AC886 had concentration-dependent inhibitory activity on the FLT3 signaling pathway in the AML cell line MV4-11, which harbors the FLT3-ITD mutation (Figure 2A). Quizartinib potently inhibited FLT3 phosphorylation $(50 \%$ inhibitory concentration $\left[\mathrm{IC}_{50}\right], 0.50 \mathrm{nM}$ ), and $\mathrm{AC} 886$ showed greater inhibition of FLT3 phosphorylation at lower concentrations, with an $\mathrm{IC}_{50}$ value of $0.18 \mathrm{nM}$. Quizartinib and AC886 similarly inhibited phosphorylation of downstream molecules SHP2, STAT5, MEK1/2, ERK1/2, and AKT (Figure 2A).

It has previously been reported that quizartinib has a slow dissociation rate from FLT3, leading to prolonged inhibition of FLT3 signaling for up to 24 hours after compound withdrawal in MV4-11 cells [26]. To assess the durability of signaling inhibition by FLT3 inhibitors in FLT3-ITD MOLM-14 cells, cells were treated with quizartinib or gilteritinib at $20 \mathrm{nM}$ for 1 hour, and then the levels of phosphorylated FLT3 and ERK were measured up to 3 hours after removal of the inhibitors from the cells. Quizartinib maintained inhibition of FLT3 phosphorylation and ERK phosphorylation through 3 hours after removal, while gilteritinib had no significant inhibitory activity starting 1 hour after removal (Figure 2B). We also assessed the long-term durability of FLT3 inhibitors, and the results indicated that quizartinib and AC886 maintained inhibition of FLT3 signaling for up to 24 hours after compound withdrawal, while midostaurin, gilteritinib, crenolanib, and sorafenib were no longer able to inhibit FLT3 signaling at 24 hours (Figure 2C).

\section{In vitro inhibitory activity of quizartinib and AC886 on the viability of FLT3-ITD AML cells}

We examined the growth inhibitory activity of the FLT3 inhibitors on both FLT3-ITD and wild-type FLT3 AML cells. Quizartinib reduced the viability of the FLT3- 
ITD AML MV4-11, MOLM-13, and MOLM-14 cells, with $\mathrm{IC}_{50}$ values of $0.40,0.89$, and $0.73 \mathrm{nM}$, respectively (Supplementary Table 3). AC886 had similar impact on FLT3-ITD AML cell viability, with $\mathrm{IC}_{50}$ values for MV411, MOLM-13, and MOLM-14 cells of $0.21,0.36$, and 0.23 $\mathrm{nM}$, respectively (Supplementary Table 3). Both quizartinib and AC886 potently inhibited the growth of wild-type FLT3 AML EOL-1 (with FIP1L-PDGFR $\alpha$ ) cells and moderately inhibited growth of Kasumi-1 (with KIT N822K) cells, but they had minimal impact on the growth of other wild-type FLT3 AML cells. Midostaurin, gilteritinib, crenolanib, and sorafenib all had less inhibitory activity on the 3 FLT3-ITD cell lines than both quizartinib and AC886, suggesting that quizartinib and AC886 exert potent antileukemic activity selectively on FLT3-ITD AML (Figure 2D; Supplementary Table 3; Supplementary Figure 1).
A

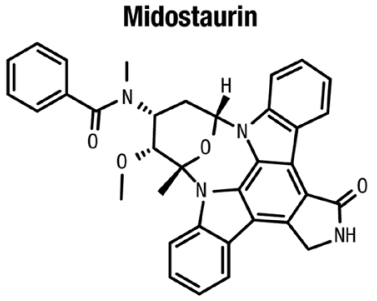

Quizartinib

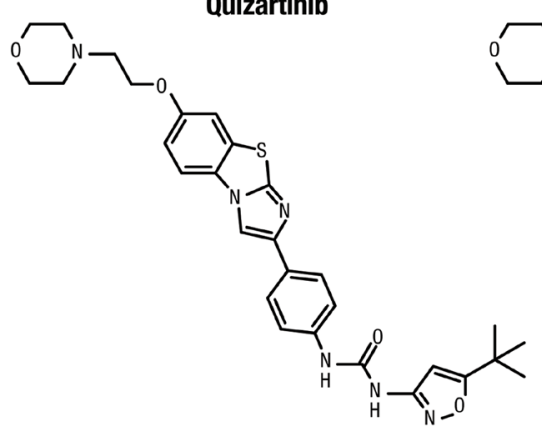

B

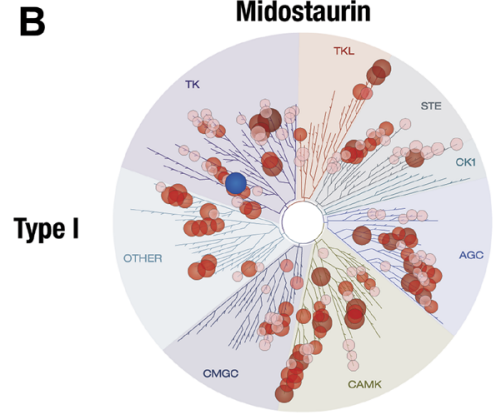

Quizartinib

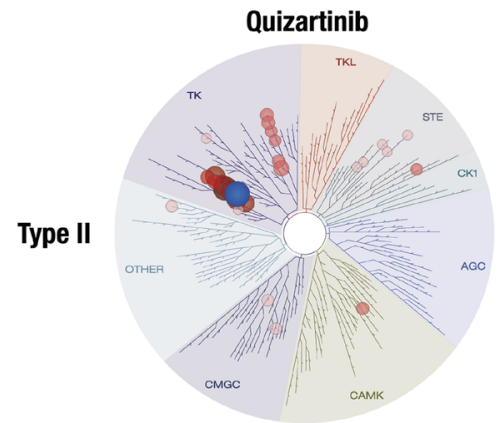<smiles>CCc1nc(C(N)=O)c(Nc2ccc(N3CCC(N4CCN(C)CC4)CC3)c(OC)c2)nc1NC1CCOCC1</smiles>

AC886

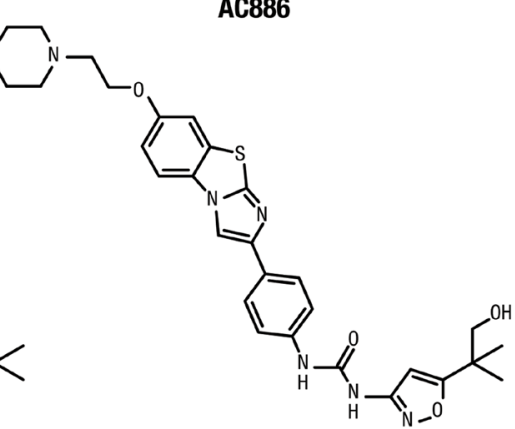

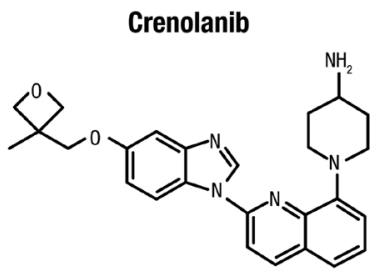

Sorafenib

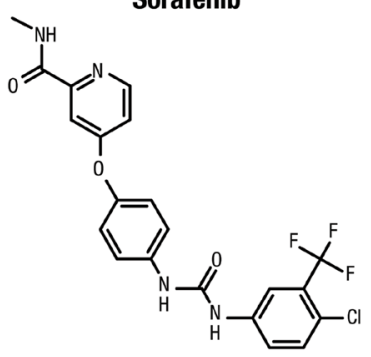

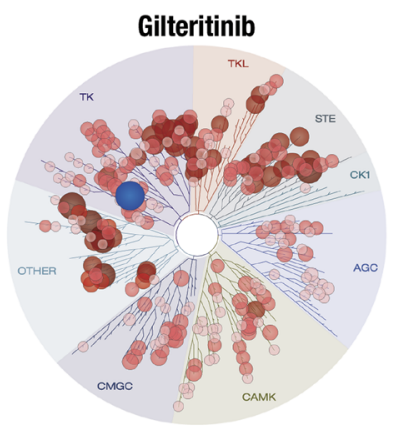

AC886

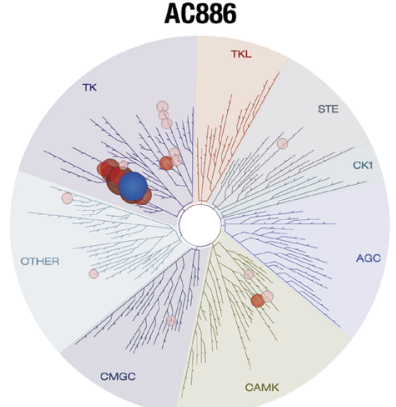

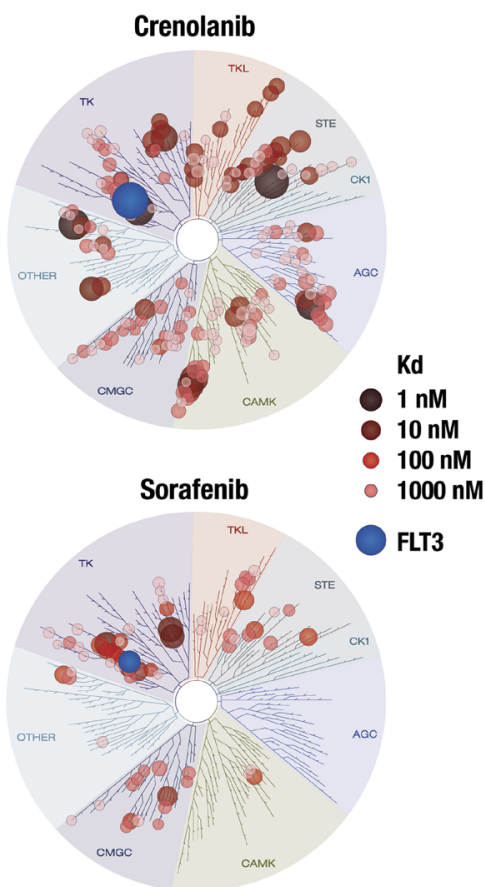

Figure 1: Chemical structure and kinase selectivity profiling of quizartinib, AC886, and other FLT3 inhibitors. (A) Chemical structures of midostaurin, gilteritinib, crenolanib, quizartinib, AC886, and sorafenib. (B) Binding affinity of compounds was measured against 404 nonmutant kinases. Kd values were calculated from duplicate 11-point dose-response curves. Each red circle represents a kinase bound to each compound. Larger circles indicate higher binding affinity of each compound to kinases. Kinases with Kd values $<3000 \mathrm{nM}$ are shown. Blue circles represent FLT3. 
Table 1: Kinase selectivity profiling of FLT3 inhibitors

\begin{tabular}{lcccccc}
\hline & \multicolumn{7}{c}{ Number of kinases } \\
\cline { 2 - 7 } Kd value & Quizartinib & AC886 & Midostaurin & Gilteritinib & Crenolanib & Sorafenib \\
\hline$<1 \mathrm{nM}$ & 0 & 1 & 0 & 1 & 4 & 0 \\
$\geq 1$ and $<10 \mathrm{nM}$ & 2 & 2 & 5 & 16 & 9 & 4 \\
$\geq 10$ and $<100 \mathrm{nM}$ & 6 & 5 & 49 & 67 & 40 & 16 \\
$\geq 100$ and $<1000 \mathrm{nM}$ & 15 & 10 & 83 & 107 & 78 & 30 \\
\hline
\end{tabular}

\section{In vivo efficacy of quizartinib and $\mathrm{AC886}$ vs other FLT3 inhibitors in a mouse xenograft model}

The antileukemic effects of quizartinib and AC886 were assessed in a mouse xenograft model in which MV4-11 cells were injected into NOD/SCID mice. Oral administration of quizartinib or AC886 inhibited tumor growth at doses ranging from 0.3 to $10 \mathrm{mg} / \mathrm{kg}$ in a dosedependent manner (each dose $P<.0001$ vs control), and both compounds had similar inhibitory effects, with $90 \%$ effective concentration $\left(\mathrm{EC}_{90}\right)$ values of 0.73 and $0.92 \mathrm{mg} / \mathrm{kg}$, respectively, without a significant impact on body weight (Figure 3A). AC886 has been identified as the major plasma metabolite of quizartinib and is rapidly converted from quizartinib in humans $[27,28]$. To evaluate the pharmacokinetic profile of AC886 after quizartinib dosing in mice, quizartinib was orally administered at a dose of $1 \mathrm{mg} / \mathrm{kg}$. In mice, the plasma concentration of quizartinib reached a maximum concentration 2 hours after administration. AC886 was detected 1 hour after quizartinib dosing, reaching its peak plasma concentration at 6 hours, suggesting that quizartinib is also rapidly converted to AC886 in mice (Supplementary Figure 2). Quizartinib demonstrated greater tumor growth inhibition than midostaurin and gilteritinib based on $\mathrm{EC}_{90}$ values (Figure 3B), using midostaurin and gilteritinib doses based on previous studies [29, 30].

\section{Quizartinib maintained inhibitory activity on the viability of midostaurin-resistant cells with $R A S$ mutations}

After long-term treatment of MOLM-14 cells with midostaurin, 2 mutations were identified that were associated with midostaurin resistance. Whole-genome sequencing revealed the mutations to be in $R A S: K R A S$ (G12A; variant allele frequency [VAF], 37\%) and NRAS (G12C; VAF, 55\%) mutations, called MOLM14-MR and MOLM-14-MR2 here, respectively. This is consistent with a previous finding of $R A S$ mutations conferring resistance to the type I inhibitor lestaurtinib [31]. Compared with parental MOLM-14 cells, a mixed population of MOLM-14 cells with either wild-type $R A S$ or midostaurin resistance-conveying $R A S$ mutations showed increased phosphorylation of FLT3 downstream signaling molecules MEK, ERK, and AKT (Figure 4A). We next assessed the impact of midostaurin resistance on the ability of quizartinib, midostaurin, and gilteritinib to inhibit cell growth. In parental MOLM-14 cells, quizartinib inhibited cell viability with the $\mathrm{IC}_{50}$ value of $0.67 \mathrm{nM}$, while midostaurin and gilteritinib had $\mathrm{IC}_{50}$ values of 10.12 and $7.87 \mathrm{nM}$, respectively (Figure 4B). While the presence of $R A S$ mutations resulted in 4- to 14-fold increases in $\mathrm{IC}_{50}$ values for all 3 compounds, quizartinib showed potent inhibition of cell growth against midostaurin-resistant cells with $\mathrm{IC}_{50}$ values of $<10 \mathrm{nM}$ (Figure 4B). We also investigated the impact of TKD mutations on FLT3 inhibitors. Quizartinib inhibited the cell viability of parental MOLM-13 cells, yet secondary FLT3 mutations D835Y and F691L conferred resistance to quizartinib (Supplementary Table 4). These results were consistent with previously reported findings and consistent with the mechanism of action of a type II inhibitor, and the same mutations were observed in patients with FLT3-ITD-positive AML with acquired resistance to quizartinib [32]. D835Y also conferred resistance to midostaurin, and F691L conferred resistance to both midostaurin and gilteritinib (Supplementary Table 4).

\section{Antileukemic activity of quizartinib in xenograft models of midostaurin-resistant cells}

We assessed the impact of midostaurin resistance on the antileukemic activity of FLT3 inhibitors in the mouse xenograft model. Quizartinib demonstrated greater tumor growth inhibition than midostaurin against tumors derived from parental MOLM-14 cells (Figure 4C). When midostaurin-resistant MOLM-14-MR cells were used, quizartinib still showed tumor growth inhibition $\left(50 \%\right.$ effective concentration $\left[\mathrm{EC}_{50}\right]$ of 3.16 vs $<1.00 \mathrm{mg} / \mathrm{kg}$ with parental MOLM-14 tumors), while midostaurin had no significant tumor growth inhibition $\left(\mathrm{EC}_{50}\right.$ of $>100 \mathrm{vs} 27.71 \mathrm{mg} / \mathrm{kg}$ with parental MOLM14 tumors) (Figure 4D). Similar results were seen with midostaurin-resistant MOLM14-MR2 cells, with quizartinib and midostaurin having $\mathrm{EC}_{50}$ values of 4.09 and $>100 \mathrm{mg} / \mathrm{kg}$, respectively (Figure 4D). Additionally, gilteritinib had weak tumor inhibition using doses in the 1 to $10 \mathrm{mg} / \mathrm{kg}$ range in the xenograft model against MOLM-14-MR2-generated tumors. 


\section{DISCUSSION}

Here we provide preclinical data characterizing quizartinib, its active metabolite AC886, and other
FLT3 inhibitors regarding kinase selectivity, extent of downstream effects of FLT3 inhibition, and activity in models of RAS-mediated midostaurin resistance. Quizartinib and AC886 were the most selective FLT3
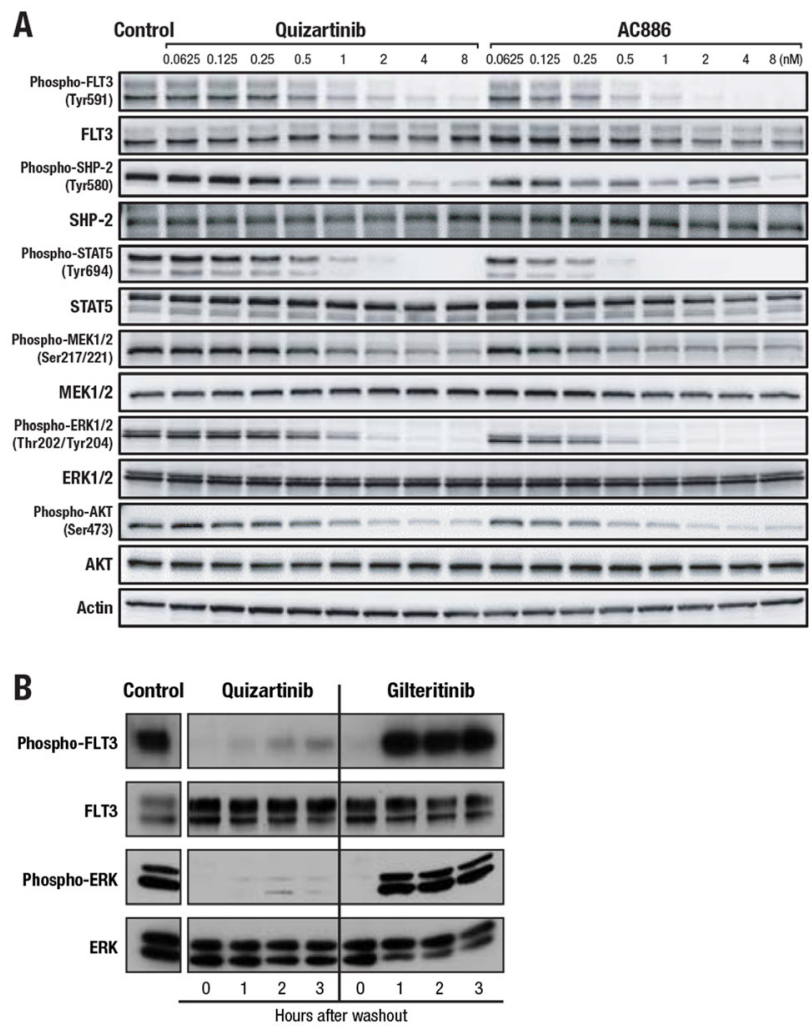

C Control Quizartinib AC886 Gilteritinib Midostaurin Crenolanib Sorafenib

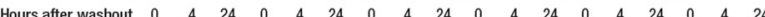

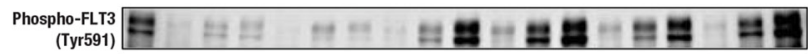

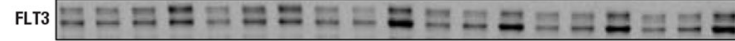

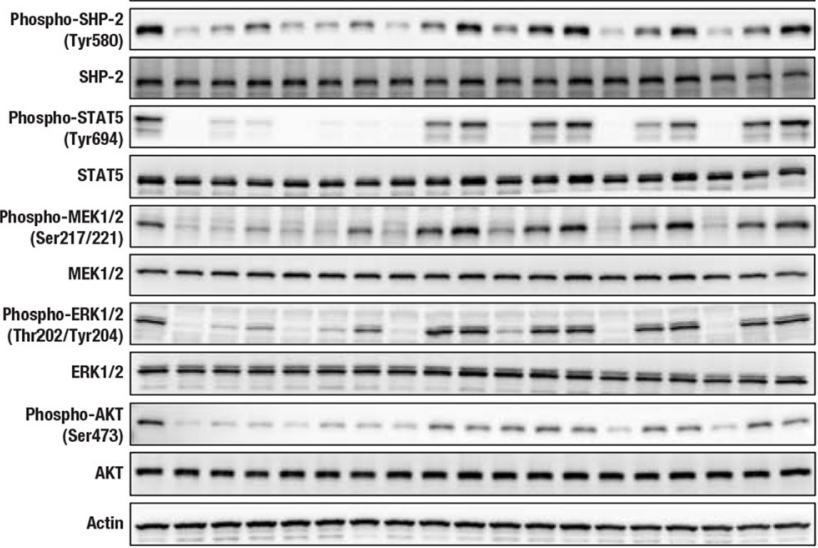

D
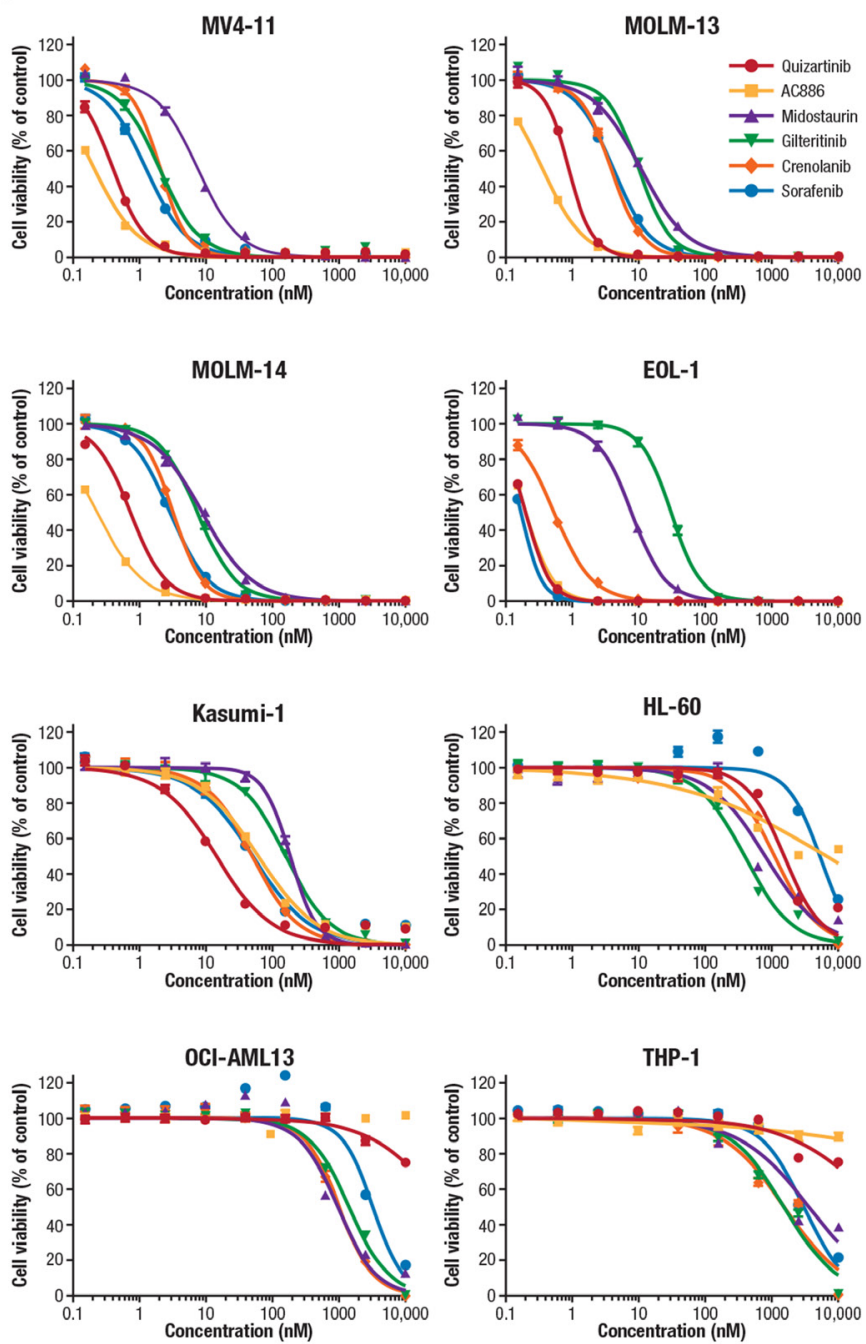

Figure 2: Inhibitory activity of quizartinib and other FLT3 inhibitors on the FLT3 signaling pathway and the viability of AML cells. (A) MV4-11 cells were treated with quizartinib or AC886 at the indicated concentrations for 2 hours. Western blot analysis was performed on cell lysates using antibodies against the indicated proteins. (B-C) MOLM-14 cells were incubated with FLT3 inhibitors at $20 \mathrm{nM}$ or with DMSO control for (B) 1 or (C) 2 hours. Cells were pelleted, washed, and resuspended in medium and incubated for (B) up to 3 hours or (C) up to 24 hours. (B) Western blot analysis was performed on FLT3 immunoprecipitants (FLT3) and whole-cell lysates (ERK). (C) Western blot analysis was performed on cell lysates using antibodies against the indicated proteins. (D) AML cells were incubated with each FLT3 inhibitor for 3 days. Cell viability was assessed using the CellTiter-Glo 2.0 Assay (Promega Corporation, Madison, Wisconsin, USA) and plotted at each concentration. Each data point and bar represent the mean and standard deviation of each concentration group, respectively $(n=3)$. 
A
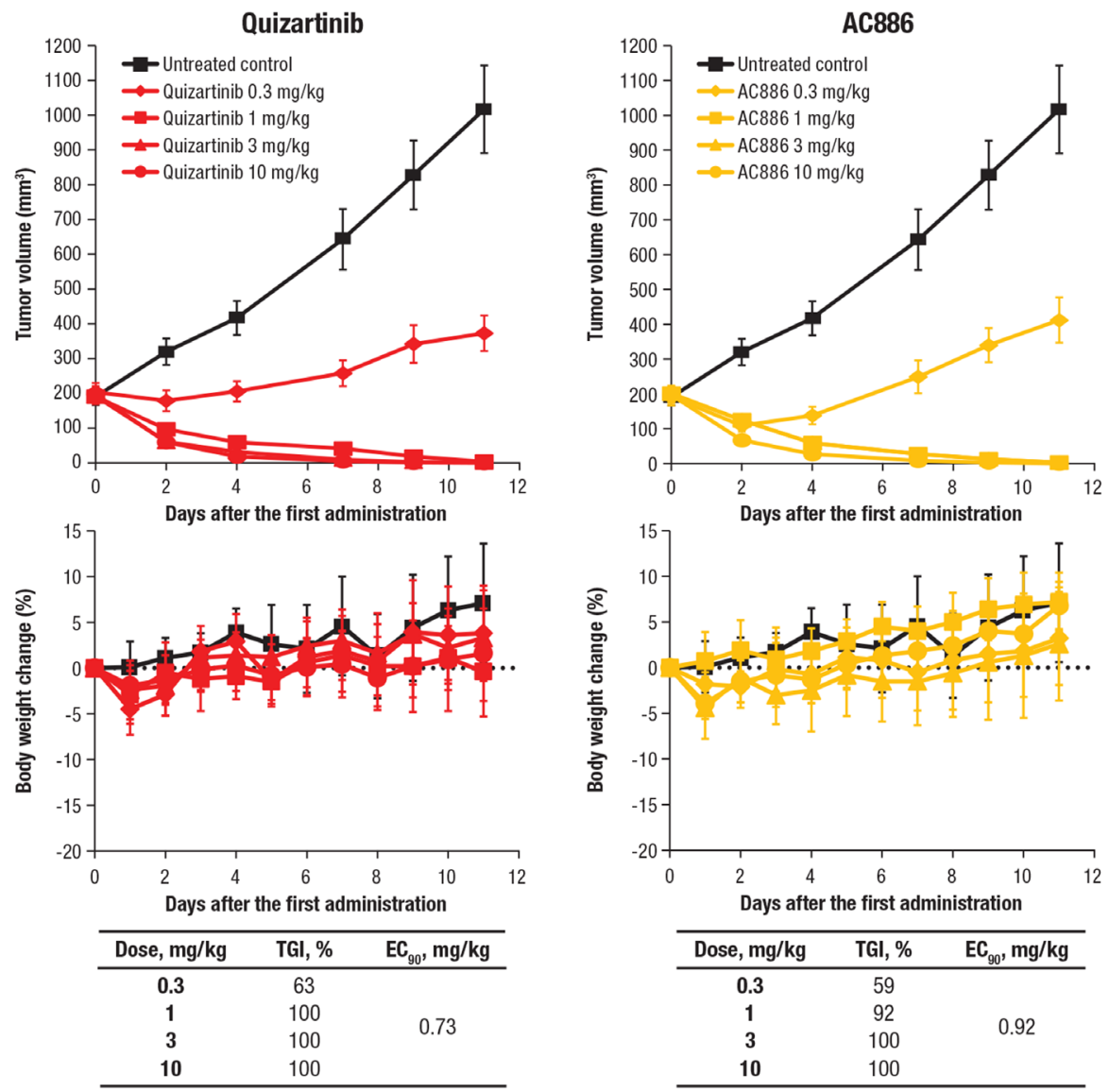

B
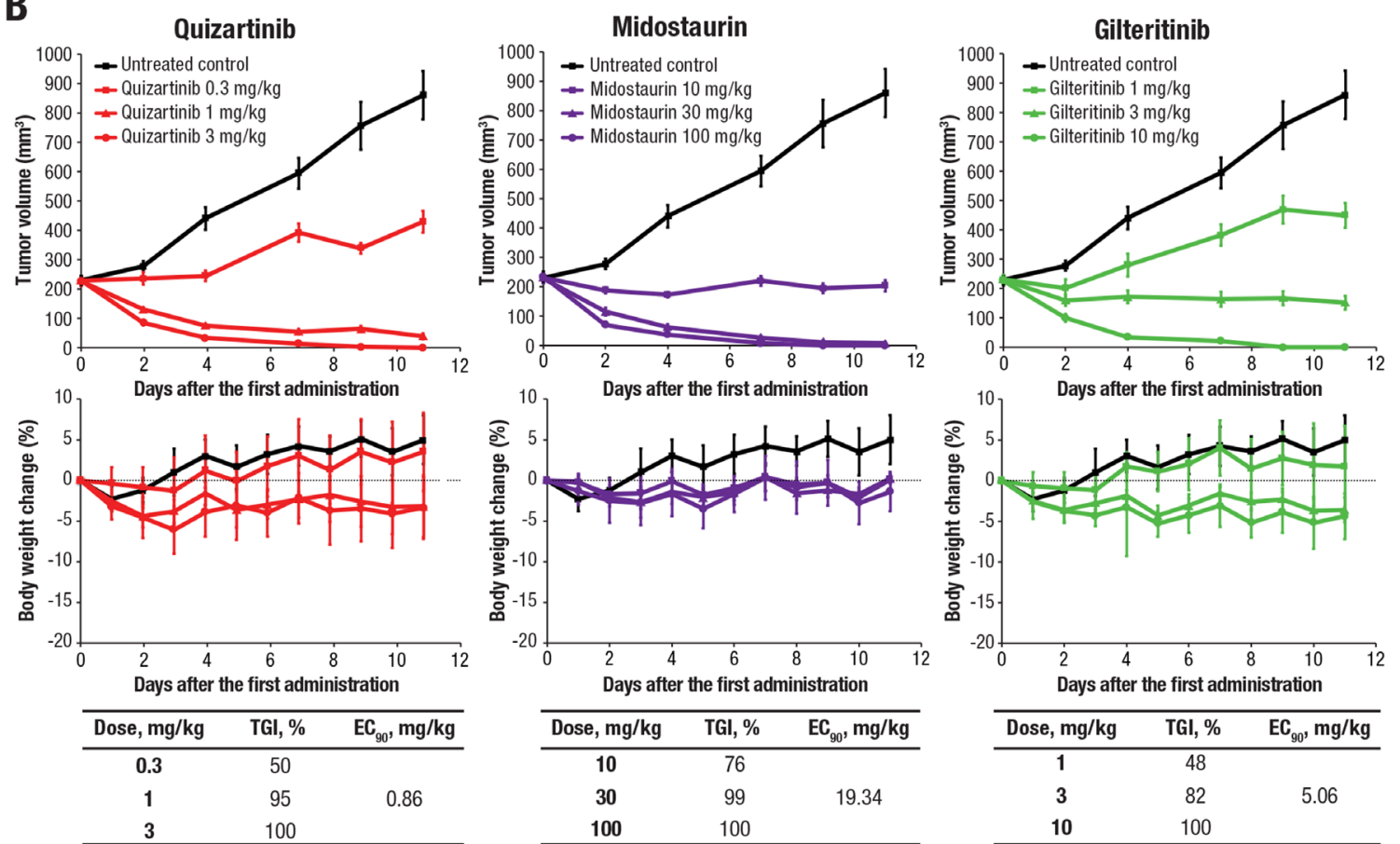

Figure 3: Quizartinib and AC886 exerted potent antitumor activity in the MV4-11 xenograft model. (A) Quizartinib and AC886 and (B) quizartinib, midostaurin, and gilteritinib were administered to mice bearing MV4-11 tumors. The upper graphs show tumor volume over time, with each data point and bar representing the mean and standard error of the estimated tumor volume in each group, respectively $(n=6)$. The lower graphs show change in body weight, with each data point and bar representing the mean and standard deviation of the percentage of body weight change in each group, respectively $(n=6)$. 
A

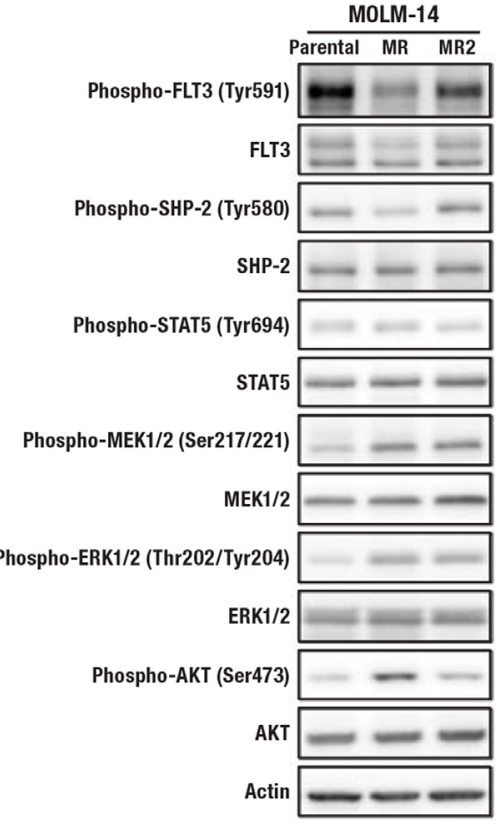

C
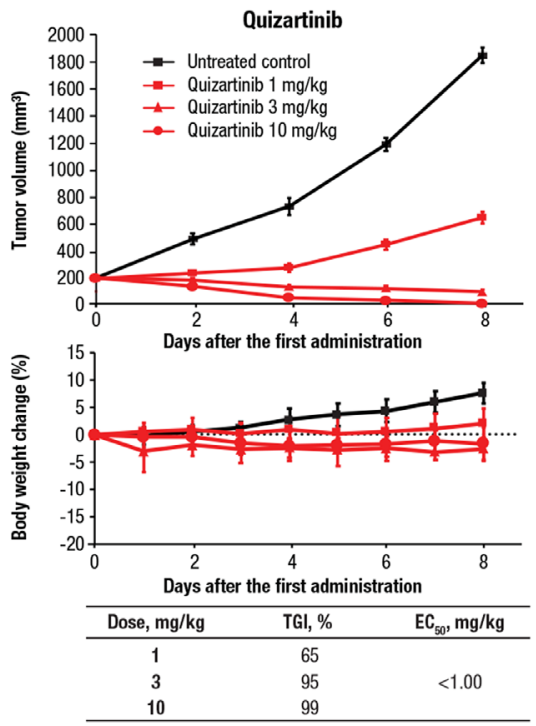

D
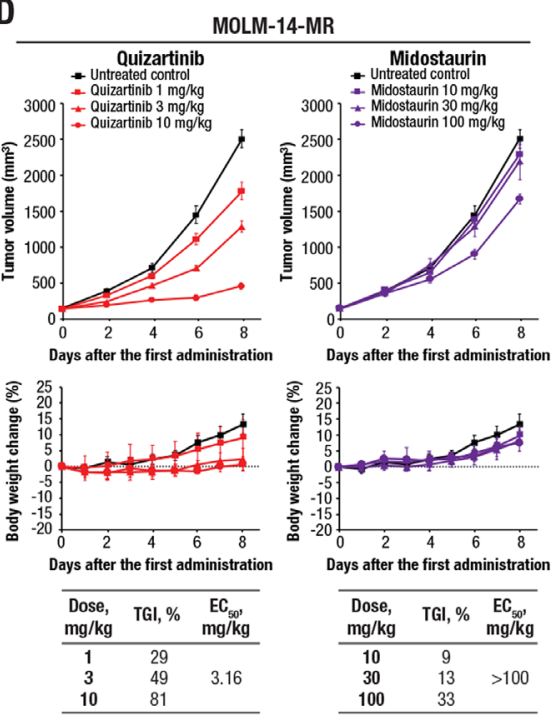
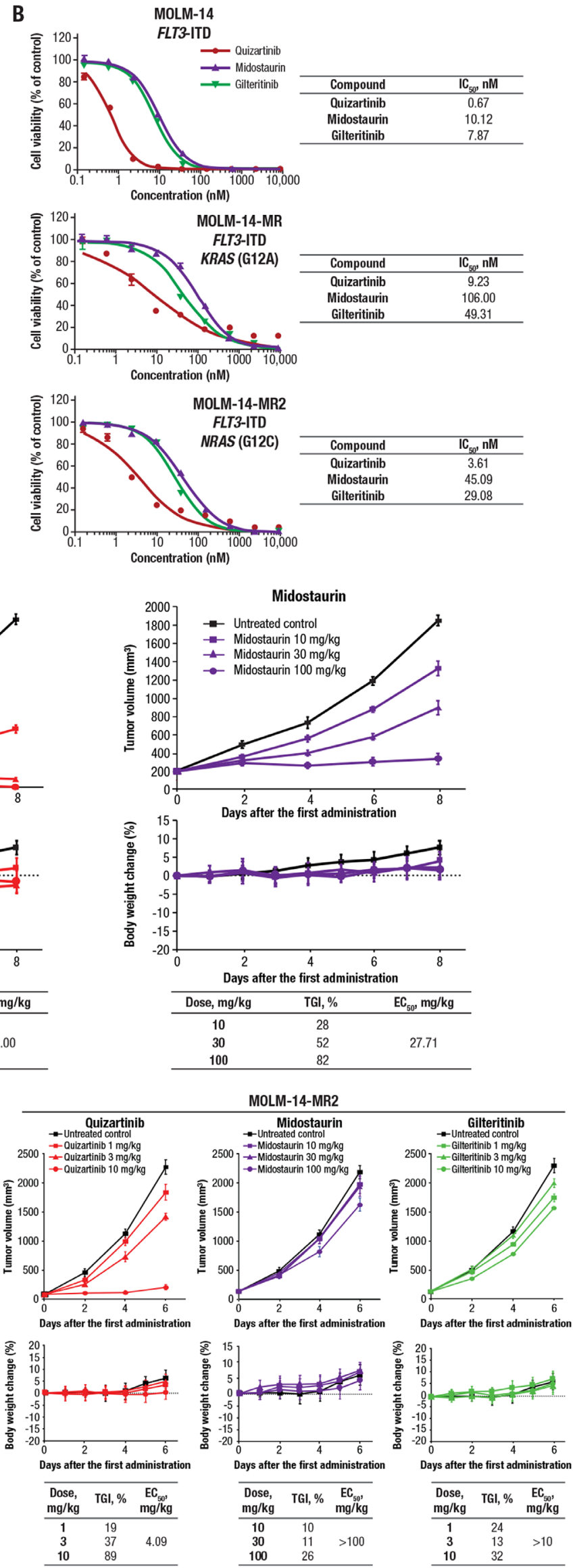
Figure 4: Quizartinib suppressed cell growth and had potent antitumor activity against midostaurin-resistant cells. (A) Cell lysates from MOLM-14, MOLM-14-MR, and MOLM-14-MR2 cells were obtained, and Western blot analysis was performed using antibodies against the indicated proteins. (B) Parental MOLM-14, MOLM-14-MR, and MOLM-14-MR2 cells were incubated with quizartinib, midostaurin, or gilteritinib for 3 days. Cell viability was assessed using the CellTiter-Glo 2.0 Assay (Promega Corporation, Madison, Wisconsin, USA) and plotted at each concentration. Each data point and bar represent the mean and standard deviation in each concentration group, respectively $(n=3)$. (C) Quizartinib or midostaurin was administered to mice bearing MOLM-14 tumors. (D) Quizartinib, midostaurin, and gilteritinib were administered to mice bearing MOLM-14-MR or MOLM-14-MR2 tumors. (C-D) The upper graphs show tumor volume over time, with each data point and bar representing the mean and standard error of the estimated tumor volume in each group, respectively $(n=6)$. The lower graphs show change in body weight, with each data point and bar representing the mean and standard deviation of the percentage of body weight change in each group, respectively $(n=6)$.

inhibitors, binding fewer kinases with high affinity than the other FLT3 inhibitors evaluated, and demonstrated high affinity for the FLT3 kinase. Quizartinib and AC886 inhibited phosphorylation of FLT3 and downstream molecules, and transient exposure to quizartinib led to durable inhibition of FLT3. Additionally, quizartinib demonstrated the greatest activity in in vitro and in vivo models of RAS-mediated midostaurin resistance.

To our knowledge, this is the first report characterizing the kinase binding profile of the FLT3 inhibitors currently in clinical development, including second-generation inhibitors, under the same experimental conditions and using the KINOMEscan technology. In this study, quizartinib and its previously uncharacterized active metabolite AC886 inhibited the FLT3-ITD receptor with greater potency and selectivity than any of the other inhibitors. Kd values for nonmutant FLT3 binding obtained in this study were consistent with those previously reported for other FLT3 inhibitors $[15,16$, 33]. In addition to having a similar kinase binding profile, quizartinib and AC886 both reduced the cell viability of FLT3-ITD cells to the same degree, and each independently had antitumor activity in a mouse xenograft model.
A notable observation of this study was that quizartinib retained antileukemic activity against midostaurin-resistant tumors. The $\mathrm{IC}_{50}$ values of quizartinib, midostaurin, and gilteritinib against established midostaurin-resistant MOLM-14 cells were 3.61 to 9.23, 45.09 to 106.00 , and 29.08 to $49.31 \mathrm{nM}$, respectively. These $\mathrm{IC}_{50}$ values were measured in culture media. It has been reported that $\mathrm{IC}_{50}$ values of quizartinib, midostaurin, and gilteritinib in plasma, which are considered to be more clinically relevant, were approximately 20-, 160-, and 20 -fold higher than those in culture media, respectively $[34,35]$. Therefore, plasma $\mathrm{IC}_{50}$ values of quizartinib, midostaurin, and gilteritinib against midostaurin-resistant MOLM-14 cells could be estimated to be approximately 72 to 180,7200 to 17,000 , and 580 to $980 \mathrm{nM}$, respectively. Since mean trough concentrations after repeated quizartinib dosing for 15 days in humans were approximately $260 \mathrm{ng} /$ $\mathrm{mL}(460 \mathrm{nM})$ for $40 \mathrm{mg}$ once a day and $440 \mathrm{ng} / \mathrm{mL}$ (780 $\mathrm{nM}$ ) for $60 \mathrm{mg}$ once a day [36], quizartinib could maintain antileukemic activity against midostaurin-resistant tumors. However, mean trough concentrations of midostaurin and gilteritinib were reported to be approximately 900 to 3600
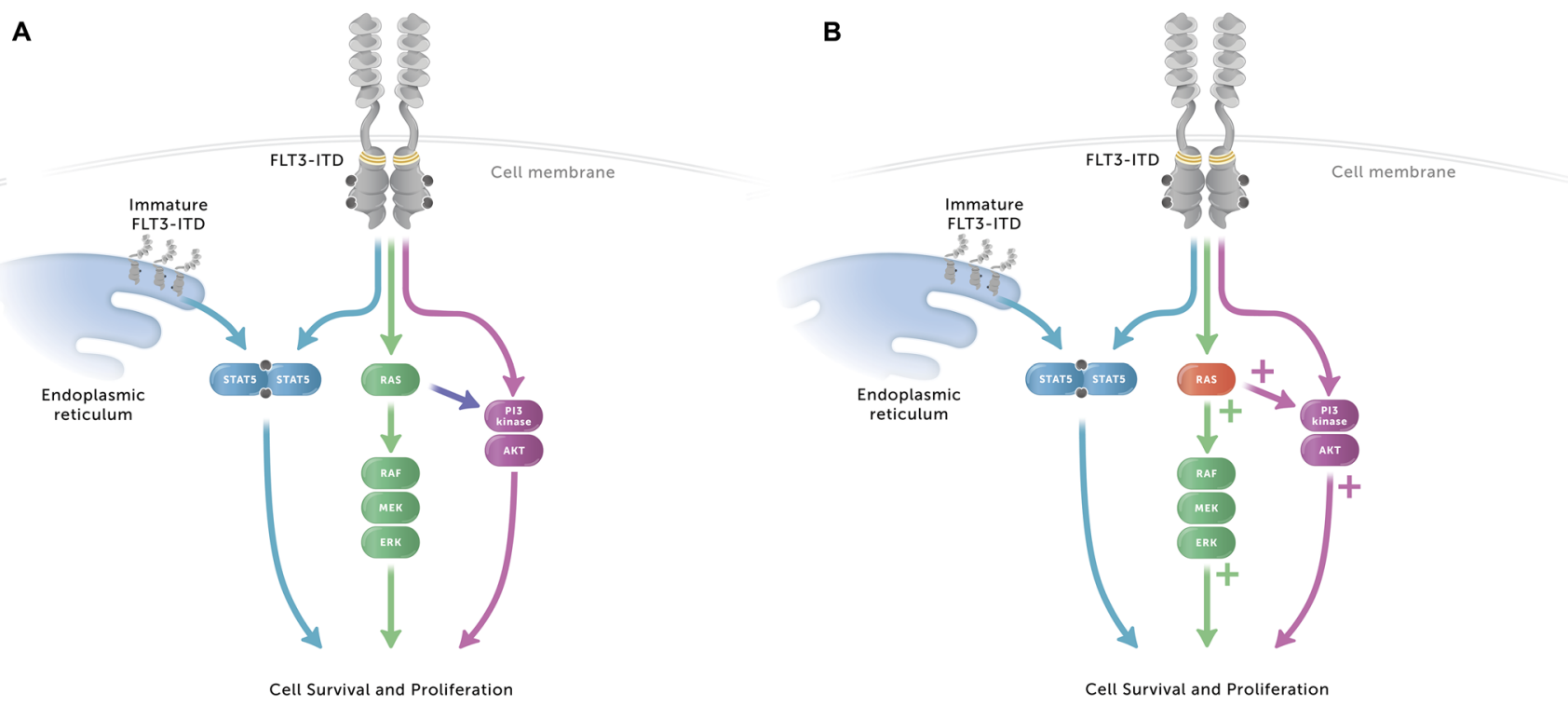

Figure 5: Signaling pathways in AML cells with FLT3-ITD with or without $R A S$ mutation granting midostaurin resistance. (A) The FLT3-ITD mutation constitutively activates FLT3 signaling, independent of FLT3 ligand. FLT3 signals through the PI3 kinase/AKT pathway, the MEK/ERK pathway, and through STAT5, both from the membrane and as an immature form from the endoplasmic reticulum. (B) When cells with $R A S$ mutations associated with midostaurin resistance make up part of the cell population, upregulation of the MEK/ERK and PI3 kinase/AKT pathways occurs, along with increased cell survival and proliferation. 
$\mathrm{ng} / \mathrm{mL}(1600-3600 \mathrm{nM})$ for midostaurin $50 \mathrm{mg}$ twice a day and $230 \mathrm{ng} / \mathrm{mL}(410 \mathrm{nM})$ for gilteritinib $120 \mathrm{mg}$ once a day $[29,37]$, which seem to be lower than the estimated plasma $\mathrm{IC}_{50}$ values of these compounds against the midostaurinresistant MOLM-14 cells.

There are multiple mechanisms by which resistance to midostaurin can develop, including secondary mutations in FLT3 that alter the binding affinity of midostaurin to FLT3 and activation of downstream signaling molecules, leading to conservation of FLT3 signaling in the presence of the inhibitor [31, 38, 39]. As FLT3-ITD mutations constitutively activate FLT3 signaling, acting through the PI3 kinase/AKT pathway, the MEK/ERK pathway, or STAT5 (Figure 5A), activation of downstream molecules in these pathways are potential mechanisms for maintaining signaling during FLT3 inhibitor exposure. In this study, NRAS and KRAS mutations in MOLM-14 cells were associated with increased phosphorylation of FLT3 downstream molecules MEK1/2, ERK1/2, and AKT and increased midostaurin resistance (Figure 5B). Activation of the signaling pathway through mutation of NRAS has previously been described as a mechanism of midostaurin resistance [31]. One possible explanation of this finding is that less potent type I FLT3 inhibitors allow for lowlevel FLT3 signaling that can be amplified and overcome by $R A S$ mutations, but these downstream mutations have a lesser impact on highly potent type II inhibitors that more completely inhibit signaling. The VAFs of $R A S$ for MOLM-14-MR and MOLM-14-MR2 were 37\% and $55 \%$, respectively, and it would be of interest to assess the impact of RAS mutations with higher VAFs on FLT3 inhibitor resistance. In addition to potent inhibition of FLT3 phosphorylation, quizartinib had sustained inhibition of FLT3 signaling, observed up to 24 hours following drug removal here and as previously described [26]. Interestingly, this effect was not observed with gilteritinib. We are currently developing FLT3-ITD cell lines with resistance to gilteritinib in order to carry out similar studies regarding cross-resistance with quizartinib and other FLT3 inhibitors. Gilteritinib has been reported to maintain activity against secondary mutations in the TKD (D835Y) [30,34], yet $R A S$ mutations were a common mechanism of acquired resistance to gilteritinib in patients with FLT3-mutated AML [40].

Quizartinib retained both in vitro activity against the proliferation of mixed FLT3-ITD cell lines with parental or midostaurin resistance-conveying NRAS and KRAS mutations and in vivo activity against midostaurin-resistant FLT3-ITD tumors with $\mathrm{EC}_{50}$ values of approximately 3 to $4 \mathrm{mg} / \mathrm{kg}$ compared with $>100 \mathrm{mg} / \mathrm{kg}$ for midostaurin and $>10 \mathrm{mg} / \mathrm{kg}$ for gilteritinib (NRAS mutated only). These results suggest the potential value of quizartinib for the treatment of patients with FLT3-ITD mutations for whom a previous midostaurin treatment regimen failed, but further clinical investigation is needed.
In conclusion, we have demonstrated the high affinity and selectivity that quizartinib and its active metabolite AC886 have for FLT3 and that quizartinib maintains preclinical antitumor activity against midostaurin-resistant tumor models. Additional clinical trials will be needed to clarify and optimize the role of quizartinib in the treatment of patients with relapsed or refractory AML who have previously been treated with midostaurin.

\section{MATERIALS AND METHODS}

\section{Reagents and cell culture}

Quizartinib dihydrochloride and its active metabolite AC886 were prepared by Daiichi Sankyo, Inc. Midostaurin, gilteritinib, crenolanib, and sorafenib were synthesized by Daiichi Sankyo Co, Ltd, for research purposes only. Each compound was dissolved in dimethyl sulfoxide (DMSO), and DMSO was used as the control treatment for in vitro experiments.

Human AML cell lines MV4-11, Kasumi-1, HL60 , and THP-1 were purchased from the American Type Culture Collection (Manassas, Virginia, USA). MV411 cells were cultured in Iscove's Modified Dulbecco's Medium (IMDM; Thermo Fisher Scientific, Waltham, Massachusetts, USA) supplemented with $10 \%$ (vol/vol) heat-inactivated fetal bovine serum (FBS; GE Healthcare Ltd, Chicago, Illinois, USA). Kasumi-1 cells were cultured in RPMI-1640 medium (FUJIFILM Wako Pure Chemical Corporation, Osaka, Japan) supplemented with 20\% (vol/ vol) heat-inactivated FBS. HL-60 cells were cultured in IMDM supplemented with $20 \%$ (vol/vol) heat-inactivated FBS. THP-1 cells were cultured in RPMI-1640 medium supplemented with $20 \%$ (vol/vol) heat-inactivated FBS and $0.05 \mathrm{mM}$ StemSure 2-Mercaptoethanol Solution (FUJIFILM Wako Pure Chemical Corporation). Human AML cell lines, MOLM-13, MOLM-14, EOL-1, and OCI-AML3, were purchased from Leibniz-Institut DSMZ-Deutsche Sammlung von Mikroorganismen und Zellkulturen GmbH. MOLM-13, MOLM-14, and EOL-1 cells were cultured in RPMI-1640 medium supplemented with $10 \%$ (vol/vol) heat-inactivated FBS, and OCI-AML3 cells were cultured in Minimum Essential Medium $\alpha$ (Thermo Fisher Scientific) supplemented with 20\% (vol/ vol) heat-inactivated FBS.

Following long-term treatment of MOLM-14 cells with midostaurin, 2 midostaurin-resistant MOLM-14 lines (MOLM-14-MR and MOLM-14-MR2) emerged. Wholeexome sequencing revealed that $K R A S$ (G12A; VAF, 37\%) and NRAS (G12C; VAF, 55\%) mutations occurred in MOLM-14-MR and MOLM-14-MR2, respectively. After long-term treatment of MOLM-13 cells with quizartinib, 2 quizartinib-resistant MOLM-13 lines (MOLM-13-QR and MOLM-13-QR2) were discovered. MOLM-13-QR contained FLT3 (D835Y; VAF, 32\%) and MOLM-13-QR2 contained FLT3 (F691L; VAF, 29\%) mutations. 


\section{Kinase binding affinity assays}

KINOMEscan kinase binding assays were performed at a Eurofins laboratory as previously described $[14,41]$.

\section{Cell viability assays}

Aliquots of cells were treated with each inhibitor at concentrations ranging from 0.153 to $10,000 \mathrm{nM}$ and cultured in the medium for 3 days. The amount of ATP in viable cells was quantified as a luminescent signal using the CellTiter-Glo 2.0 Assay (Promega Corporation, Madison, Wisconsin, USA) and EnVision (PerkinElmer Inc, Waltham, Massachusetts, USA) to determine the number of viable cells according to the manufacturers' instructions.

\section{FLT3 signaling pathway analysis}

MV4-11, MOLM-14, MOLM-14-MR, and MOLM14-MR2 cells were used for FLT3 signaling pathway analysis. MV4-11 cells were treated with quizartinib or AC886 at concentrations ranging from 0.0625 to $8 \mathrm{nM}$ for 2 hours. After centrifugation, the cell pellets were washed by ice-cold Dulbecco's Phosphate-Buffered Saline (FUJIFILM Wako Pure Chemical Corporation), suspended, and lysed in cell lysis buffer (Cell Signaling Technology, Inc, Danvers, Massachusetts, USA) containing cOmplete (Roche Diagnostics, Basel, Switzerland) and PhosSTOP (Roche Diagnostics). After centrifugation, supernatants were used as cell lysates. The cell lysates were resolved by sodium dodecyl sulfate-polyacrylamide gel electrophoresis, followed by immunoblotting. Phospho-FLT3 (Tyr591), total FLT3, phospho-SHP-2 (Tyr580), total SHP-2, phospho-STAT5 (Tyr694), phospho-MEK1/2 (Ser217/221), total MEK1/2, phospho-ERK1/2 (Thr202/Tyr204), total ERK1/2, phospho-AKT (Ser473), total AKT, and $\beta$-actin were probed with corresponding rabbit antibodies (Catalog No. 3461, 3462, 3703, 3397, 4322, 9121, 9126, 4370, 4695, 4058, 9272, and 4970, respectively; Cell Signaling Technology, Inc) as primary antibodies. Total STAT5 was also probed with corresponding rabbit antibody (Catalog No. ab194898; Abcam plc, Cambridge, UK). Horseradish peroxidase-conjugated goat antirabbit IgG (Cell Signaling Technology, Inc) was used as a secondary antibody. Immunoblotting detection was performed with Luminata Forte Western HRP Substrate (Merck KGaA, Darmstadt, Germany) and Fusion FX7 (Vilber Lourmat, Collegien, France) or ImageQuant LAS 4000 mini (GE Healthcare) according to the manufacturers' instructions.

\section{FLT3 inhibitor washout experiment}

MOLM-14 cells in RPMI-1640/10\% FBS were adjusted to a concentration of 1 million cells $/ \mathrm{mL}$.
Quizartinib, AC886, gilteritinib, midostaurin, crenolanib, and sorafenib in DMSO were diluted in culture medium. An aliquot of cells was removed (baseline). Cells were incubated for 1 or 2 hours in a $\mathrm{CO}_{2}$ incubator at $37^{\circ} \mathrm{C}$ with quizartinib, AC886, gilteritinib, midostaurin, crenolanib, or sorafenib, all at a concentration of $20 \mathrm{nM}$, or DMSO control. Another aliquot of cells was removed (0-hour control). Cells were then pelleted, washed once in conditioned medium, and resuspended in conditioned medium at 1 million cells $/ \mathrm{mL}$. Aliquots of cells were removed after 1, 2, 3, 4, or 24 hours of incubation.

Upon removal from culture, cells were pelleted, washed in phosphate-buffered saline, lysed in detergent buffer, and subject to immunoprecipitation and Western blotting. FLT3 was immunoprecipitated with rabbit antiFLT3 (S-18; Santa Cruz, Dallas, Texas, USA), followed by Western blotting with antiphosphotyrosine (4G10; Millipore, Burlington, Massachusetts, USA). Wholecell lysate was directly analyzed by Western blotting for ERK and phospho-ERK (Cell Signaling Technology, Inc). Alternatively, the cell lysates were analyzed as described in "FLT3 signaling pathway analysis."

\section{In vivo xenograft mouse models}

Specific pathogen-free female NOD SCID mice (NOD/ShiJic-scid Jcl), aged 5 weeks, for the MV4-11 xenograft model, and specific pathogen-free female SCID mice (Fox Chase SCID C.B-17/Icr-scid/scidJcl), aged 6 weeks, for the MOLM-14 xenograft model, were purchased from CLEA Japan, Inc (Tokyo, Japan).

The in vitro cultured MV4-11 cells were transplanted subcutaneously into female NOD SCID mice at $1 \times 10^{7}$ cells/mouse, and MOLM-14, MOLM-14-MR, or MOLM14-MR2 cells were transplanted into female SCID mice at $5 \times 10^{6}$ cells/mouse. When the average estimated tumor volume was $>100 \mathrm{~mm}^{3}$, mice were randomly grouped on the basis of the estimated tumor volume by using the management system for animal experimental data (SMAD; JMACSOFT Corp, Nagaoka, Japan). The grouping day was defined as day 0 , and each group consisted of 6 mice that received each treatment. Quizartinib and AC886 were dissolved in $22 \%$ hydroxypropyl- $\beta$-cyclodextrin (Tokyo Chemical Industry Co, Ltd, Tokyo, Japan). Midostaurin and gilteritinib were dissolved in $0.5 \%(\mathrm{wt} / \mathrm{vol})$ sterilized methyl cellulose 400 solution (FUJIFILM Wako Pure Chemical Industries, Ltd). Each compound was orally administered once per day at indicated doses as a free base. The tumor length (L) and width (W) in millimeters were measured using a digital caliper (CD-15CX; Mitutoyo Corporation, Kanagawa, Japan), and the mouse body weight was measured with a digital balance for animals (UW2200H; Shimadzu Corporation, Kyoto, Japan). The estimated tumor volume of each mouse was automatically calculated in the SMAD according to the following equation: Estimated tumor volume $\left(\mathrm{mm}^{3}\right)=1 / 2 \times \mathrm{L} \times \mathrm{W}^{2}$. 
Mean estimated tumor volume was determined for the compound-treated (T) and untreated control (C) groups. Tumor growth inhibition was automatically calculated in the SMAD according to the following equation: Tumor growth inhibition $(\%)=(1-\mathrm{T} / \mathrm{C}) \times 100$. All animal experimental procedures were performed according to the guidelines of the Institutional Animal Care and Use Committee of Daiichi Sankyo Co, Ltd.

\section{Statistical analysis}

For estimated change in tumor volume with each inhibitor, a parametric Dunnett test was conducted between the $\mathrm{T}$ and $\mathrm{C}$ groups to evaluate the antitumor activity of the compound. A 2 -sided $P$ value of $<0.05$ was considered statistically significant. Hypothesis testing of Spearman rank correlation coefficient (the null hypothesis correlation coefficient is 0 ) was conducted among the $\mathrm{T}$ and $\mathrm{C}$ groups to evaluate the dose-dependent antitumor activity of the compound. All statistical analyses were performed using REDPOST/BI (SAS System Release 9.2; SAS Institute Inc, Cary, North Carolina, USA).

The $\mathrm{IC}_{50}(\mathrm{nM})$, the $\mathrm{EC}_{50}(\mathrm{mg} / \mathrm{kg})$, and the $\mathrm{EC}_{90}(\mathrm{mg} / \mathrm{kg})$ were estimated using REDPOST/BI.

\section{Abbreviations}

AML: acute myeloid leukemia; DMSO: dimethyl sulfoxide; $\mathrm{EC}_{50}: 50 \%$ effective concentration; $\mathrm{EC}_{90}$ : 90\% effective concentration; FBS: fetal bovine serum; FLT3: FMS like tyrosine kinase $3 ; \mathrm{IC}_{50}: 50 \%$ inhibitory concentration; IMDM: Iscove's Modified Dulbecco's Medium; ITD: internal tandem duplication; TKD: tyrosine kinase domain; VAF: variant allele frequency.

\section{Author contributions}

Conception and design: T. Aikawa, K. Iwanaga, Y. Nishiya, S. Inoue, T. Isoyama; development of methodology: T. Aikawa, N. Togashi, K. Iwanaga, Y. Nishiya, T. Isoyama; acquisition of data: T. Aikawa, N. Togashi, K. Iwanaga, H. Okada, Y. Nishiya, M. J. Levis; analysis and interpretation of data: T. Aikawa, N. Togashi, K. Iwanaga, H. Okada, Y. Nishiya, S. Inoue, M. J. Levis, T. Isoyama; writing, review and/or revision of the manuscript: T. Aikawa, N. Togashi, K. Iwanaga, H. Okada, Y. Nishiya, S. Inoue, M. J. Levis, T. Isoyama; administrative, technical, or material support: N. Togashi; study supervision: M. J. Levis, T. Isoyama. All authors reviewed drafts of the manuscript and approved the final manuscript for submission.

\section{ACKNOWLEDGMENTS}

We thank S. Takahashi, Y. Yamamoto, and E. Kumazawa at Daiichi Sankyo RD Novare Co, Ltd, for technical support in in vivo experiments; T. Hirata and N.
Wada at Daiichi Sankyo RD Novare Co, Ltd, for wholeexome sequencing; and K. Ito at Daiichi Sankyo Co, Ltd, for technical support in in vitro experiments. We also thank K. Fujiwara at Daiichi Sankyo Co, Ltd, for fruitful discussions on study design. Medical writing support was provided by Scott Battle, PhD, of Medical Expressions, funded by Daiichi Sankyo, Inc.

\section{CONFLICTS OF INTEREST}

MJL is a consultant for Agios, Amgen, Astellas, Daiichi Sankyo Co, Ltd, Fujifilm, Menarini, and Novartis and has received research funding from Astellas, Novartis, and Fujifilm. All other authors are employees of Daiichi Sankyo Co, Ltd.

\section{FUNDING}

This study was funded by Daiichi Sankyo, Inc, and Daiichi Sankyo Co, Ltd.

\section{REFERENCES}

1. Stirewalt DL, Radich JP. The role of FLT3 in haematopoietic malignancies. Nat Rev Cancer. 2003; 3:650-665. https:// doi.org/10.1038/nrc1169. [PubMed]

2. Gilliland DG, Griffin JD. The roles of FLT3 in hematopoiesis and leukemia. Blood. 2002; 100:1532-1542. https://doi.org/10.1182/blood-2002-02-0492. [PubMed]

3. Levis M, Small D. FLT3: ITDoes matter in leukemia. Leukemia. 2003; 17:1738-1752. https://doi.org/10.1038/ sj.leu.2403099. [PubMed]

4. Fröhling S, Schlenk RF, Breitruck J, Benner A, Kreitmeier S, Tobis K, Döhner H, Döhner K; AML Study Group Ulm. Acute myeloid leukemia. Prognostic significance of activating FLT3 mutations in younger adults (16 to 60 years) with acute myeloid leukemia and normal cytogenetics: a study of the AML Study Group Ulm. Blood. 2002; 100:4372-4380. https://doi.org/10.1182/ blood-2002-05-1440. [PubMed]

5. Schnittger S, Schoch C, Dugas M, Kern W, Staib P, Wuchter C, Loffler H, Sauerland CM, Serve H, Büchner T, Haferlach T, Hiddemann W. Analysis of FLT3 length mutations in 1003 patients with acute myeloid leukemia: correlation to cytogenetics, FAB subtype, and prognosis in the AMLCG study and usefulness as a marker for the detection of minimal residual disease. Blood. 2002; 100:59-66. https:// doi.org/10.1182/blood.V100.1.59. [PubMed]

6. Wagner K, Damm F, Thol F, Göhring G, Görlich K, Heuser M, Schäfer I, Schlegelberger B, Heil G, Ganser A, Krauter J. FLT3-internal tandem duplication and age are the major prognostic factors in patients with relapsed acute myeloid leukemia with normal karyotype. Haematologica. 2011; 96:681-686. https://doi.org/10.3324/haematol.2010.034074. [PubMed] 
7. Ravandi F, Kantarjian H, Faderl S, Garcia-Manero G, O'Brien S, Koller C, Pierce S, Brandt M, Kennedy D, Cortes J, Beran M. Outcome of patients with FLT3-mutated acute myeloid leukemia in first relapse. Leuk Res. 2010; 34:752-756. https://doi.org/10.1016/j.leukres.2009.10.001. [PubMed]

8. Levis M. FLT3 mutations in acute myeloid leukemia: what is the best approach in 2013? Hematology Am Soc Hematol Educ Program. 2013; 2013:220-226. https://doi. org/10.1182/asheducation-2013.1.220. [PubMed]

9. Choudhary C, Schwäble J, Brandts C, Tickenbrock L, Sargin B, Kindler T, Fischer T, Berdel WE, Müller-Tidow C, Serve H. AML-associated Flt3 kinase domain mutations show signal transduction differences compared with Flt3 ITD mutations. Blood. 2005; 106:265-273. https://doi. org/10.1182/blood-2004-07-2942. [PubMed]

10. Natarajan K, Xie Y, Burcu M, Linn DE, Qiu Y, Baer MR. Pim-1 kinase phosphorylates and stabilizes $130 \mathrm{kDa}$ FLT3 and promotes aberrant STAT5 signaling in acute myeloid leukemia with FLT3 internal tandem duplication. PLoS One. 2013; 8:e74653. https://doi.org/10.1371/journal. pone.0074653. [ [PubMed]

11. Larrosa-Garcia M, Baer MR. FLT3 inhibitors in acute myeloid leukemia: current status and future directions. Mol Cancer Ther. 2017; 16:991-1001. https://doi. org/10.1158/1535-7163.MCT-16-0876. [PubMed]

12. Zorn JA, Wang Q, Fujimura E, Barros T, Kuriyan J. Crystal structure of the FLT3 kinase domain bound to the inhibitor quizartinib (AC220). PLoS One. 2015; 10:e0121177. https://doi.org/10.1371/journal.pone.0121177. [PubMed]

13. Smith CC, Zhang C, Lin KC, Lasater EA, Zhang T, Massi E, Damon LE, Pendleton M, Bashir A, Sebra R, Perl A, Kasarskis A, Shellooe R, et al. Characterizing and overriding the structural mechanism of the quizartinibresistant FLT3 "gatekeeper" F691L mutation with PLX3397. Cancer Discov. 2015; 5:668-679. https://doi. org/10.1158/2159-8290.CD-15-0060. [PubMed]

14. Karaman MW, Herrgard S, Treiber DK, Gallant P, Atteridge CE, Campbell BT, Chan KW, Ciceri P, Davis MI, Edeen PT, Faraoni R, Floyd M, Hunt JP, et al. A quantitative analysis of kinase inhibitor selectivity. Nat Biotechnol. 2008; 26:127-132. https://doi.org/10.1038/nbt1358. [PubMed]

15. Davis MI, Hunt JP, Herrgard S, Ciceri P, Wodicka LM, Pallares G, Hocker M, Treiber DK, Zarrinkar PP. Comprehensive analysis of kinase inhibitor selectivity. Nat Biotechnol. 2011; 29:1046-1051. https://doi.org/10.1038/ nbt.1990. [PubMed]

16. Zarrinkar PP, Gunawardane RN, Cramer MD, Gardner MF, Brigham D, Belli B, Karaman MW, Pratz KW, Pallares G, Chao Q, Sprankle KG, Patel HK, Levis M, et al. AC220 is a uniquely potent and selective inhibitor of FLT3 for the treatment of acute myeloid leukemia (AML). Blood. 2009; 114:2984-2992. https://doi.org/10.1182/ blood-2009-05-222034. [PubMed]
17. Ding L, Ley TJ, Larson DE, Miller CA, Koboldt DC, Welch JS, Ritchey JK, Young MA, Lamprecht T, McLellan MD, McMichael JF, Wallis JW, Lu C, et al. Clonal evolution in relapsed acute myeloid leukaemia revealed by wholegenome sequencing. Nature. 2012; 481:506-510. https:// doi.org/10.1038/nature10738. [PubMed]

18. Ghiaur G, Levis M. Mechanisms of resistance to FLT3 inhibitors and the role of the bone marrow microenvironment. Hematol Oncol Clin North Am. 2017; 31:681-692. https:// doi.org/10.1016/j.hoc.2017.04.005. [PubMed]

19. Rydapt (midostaurin) [package insert]. East Hanover, NJ: Novartis Pharmaceuticals Corporation; 2019.

20. Rydapt (midostaurin) [summary of product characteristics]. Dublin, Ireland: Novartis Europharm Limited; 2019.

21. Xospata (gilteritinib) [package insert]. Northbrook, IL: Astellas Pharma US, Inc; 2019.

22. Xospata (gilteritinib) [package insert]. Tokyo, Japan: Astellas Pharma, Inc; 2019.

23. Xospata (gilteritinib) [summary of product characteristics]. Leiden, The Netherlands: Astellas Pharma Europe B.V.; 2019.

24. Cortes JE, Khaled S, Martinelli G, Perl AE, Ganguly S, Russell N, Krämer A, Dombret H, Hogge D, Jonas BA, Leung AY, Mehta P, Montesinos P, et al. Quizartinib versus salvage chemotherapy in relapsed or refractory FLT3-ITD acute myeloid leukaemia (QuANTUM-R): a multicentre, randomised, controlled, open-label, phase 3 trial. Lancet Oncol. 2019; 20:984-997. https://doi.org/10.1016/S14702045(19)30150-0. [PubMed]

25. Alfayez MK, Kantarjian HM, Ravandi F, Konopleva MY, Garcia-Manero G, Kadia TM, Jabbour EJ, Borthakur G, DiNardo CD, Estrov ZE, Pemmaraju N, Pierce SA, Yilmaz $\mathrm{ME}$, et al. Outcomes with subsequent FLT3-inhibitor (FLT3i) based therapies in FLT3-mutated $(\mathrm{mu})$ patients (pts) refractory/relapsed (R/R) to one or more prior FLT3 inhibitor based therapies: a single center experience. Blood. 2018; 132:663.

26. Gunawardane RN, Nepomuceno RR, Rooks AM, Hunt JP, Ricono JM, Belli B, Armstrong RC. Transient exposure to quizartinib mediates sustained inhibition of FLT3 signaling while specifically inducing apoptosis in FLT3-activated leukemia cells. Mol Cancer Ther. 2013; 12:438-447. https:// doi.org/10.1158/1535-7163.MCT-12-0305. [PubMed]

27. Sanga M, James J, Marini J, Gammon G, Hale C, Li J. An open-label, single-dose, phase 1 study of the absorption, metabolism and excretion of quizartinib, a highly selective and potent FLT3 tyrosine kinase inhibitor, in healthy male subjects, for the treatment of acute myeloid leukemia. Xenobiotica. 2017; 47:856-869. https://doi.org/10.1080/0 0498254.2016.1217100. [PubMed]

28. Cortes JE, Kantarjian H, Foran JM, Ghirdaladze D, Zodelava M, Borthakur G, Gammon G, Trone D, Armstrong RC, James J, Levis M. Phase I study of quizartinib administered daily to patients with relapsed or 
refractory acute myeloid leukemia irrespective of FMSlike tyrosine kinase 3-internal tandem duplication status. J Clin Oncol. 2013; 31:3681-3687. https://doi.org/10.1200/ JCO.2013.48.8783. [PubMed]

29. Center for Drug Evaluation and Research. Clinical pharmacology and biopharmaceutics review(s): Rydapt. https:/www.accessdata.fda.gov/drugsatfda_docs/nda/2017/20 7997Orig1Orig2s000ClinPharmR.pdf. Accessed 20 May 2019.

30. Mori M, Kaneko N, Ueno Y, Yamada M, Tanaka R, Saito R, Shimada I, Mori K, Kuromitsu S. Gilteritinib, a FLT3/AXL inhibitor, shows antileukemic activity in mouse models of FLT3 mutated acute myeloid leukemia. Invest New Drugs. 2017; 35:556-565. https://doi.org/10.1007/s10637-0170470-z. [PubMed]

31. Piloto O, Wright M, Brown P, Kim KT, Levis M, Small D. Prolonged exposure to FLT3 inhibitors leads to resistance via activation of parallel signaling pathways. Blood. 2007; 109:1643-1652. https://doi.org/10.1182/ blood-2006-05-023804. [PubMed]

32. Smith CC, Wang Q, Chin CS, Salerno S, Damon LE, Levis MJ, Perl AE, Travers KJ, Wang S, Hunt JP, Zarrinkar PP, Schadt EE, Kasarskis A, et al. Validation of ITD mutations in FLT3 as a therapeutic target in human acute myeloid leukaemia. Nature. 2012; 485:260-263. https://doi. org/10.1038/nature11016. [PubMed]

33. Zimmerman EI, Turner DC, Buaboonnam J, Hu S, Orwick S, Roberts MS, Janke LJ, Ramachandran A, Stewart CF, Inaba H, Baker SD. Crenolanib is active against models of drug-resistant FLT3-ITD-positive acute myeloid leukemia. Blood. 2013; 122:3607-3615. https://doi.org/10.1182/ blood-2013-07-513044. [PubMed]

34. Lee LY, Hernandez D, Rajkhowa T, Smith SC, Raman JR, Nguyen B, Small D, Levis M. Preclinical studies of gilteritinib, a next-generation FLT3 inhibitor. Blood. 2017; 129:257-260. https://doi.org/10.1182/ blood-2016-10-745133. [PubMed]

35. Levis M. Quizartinib for the treatment of FLT3/ITD acute myeloid leukemia. Future Oncol. 2014; 10:1571-1579. https://doi.org/10.2217/fon.14.105. [
36. Sandmaier BM, Khaled S, Oran B, Gammon G, Trone D, Frankfurt O. Results of a phase 1 study of quizartinib as maintenance therapy in subjects with acute myeloid leukemia in remission following allogeneic hematopoietic stem cell transplant. Am J Hematol. 2018; 93:222-231. https://doi.org/10.1002/ajh.24959. [PubMed]

37. Perl AE, Altman JK, Cortes J, Smith C, Litzow M, Baer MR, Claxton D, Erba HP, Gill S, Goldberg S, Jurcic JG, Larson RA, Liu C, et al. Selective inhibition of FLT3 by gilteritinib in relapsed or refractory acute myeloid leukaemia: a multicentre, first-in-human, open-label, phase 1-2 study. Lancet Oncol. 2017; 18:1061-1075. https://doi. org/10.1016/S1470-2045(17)30416-3. [PubMed]

38. Heidel F, Solem FK, Breitenbuecher F, Lipka DB, Kasper S, Thiede MH, Brandts C, Serve H, Roesel J, Giles F, Feldman E, Ehninger G, Schiller GJ, et al. Clinical resistance to the kinase inhibitor PKC412 in acute myeloid leukemia by mutation of Asn-676 in the FLT3 tyrosine kinase domain. Blood. 2006; 107:293-300. https://doi.org/10.1182/ blood-2005-06-2469. [PubMed]

39. Staudt D, Murray HC, McLachlan T, Alvaro F, Enjeti AK, Verrills NM, Dun MD. Targeting oncogenic signaling in mutant FLT3 acute myeloid leukemia: the path to least resistance. Int J Mol Sci. 2018; 19:3198. https://doi. org/10.3390/ijms19103198. [PubMed]

40. McMahon CM, Ferng T, Canaani J, Wang ES, Morrissette JJD, Eastburn DJ, Pellegrino M, Durruthy-Durruthy R, Watt CD, Asthana S, Lasater EA, DeFilippis R, Peretz CAC, et al. Clonal selection with RAS pathway activation mediates secondary clinical resistance to selective FLT3 inhibition in acute myeloid leukemia. Cancer Discov. 2019; 9:10501063. https://doi.org/10.1158/2159-8290.CD-18-1453. [PubMed]

41. Fabian MA, Biggs WH 3rd, Treiber DK, Atteridge CE, Azimioara MD, Benedetti MG, Carter TA, Ciceri P, Edeen PT, Floyd M, Ford JM, Galvin M, Gerlach JL, et al. A small molecule-kinase interaction map for clinical kinase inhibitors. Nat Biotechnol. 2005; 23:329-336. https://doi. org/10.1038/nbt1068. [PubMed] 